\title{
Expansão e racionalização do consumo de energia elétrica
}

\section{PIETRO ERBER}

Assistente da Diretoria de Planejamento e Engenharia da ELETROBRÁS. Engenheiro, foi chefe do Departamento de Mercado da ELETROBRÁS.

ste artigo enfoca as perspectivas de expansão do uso da energia elétrica, tendo em vis. ta os fatores relevantes do crescimento de sua demanda, em parti. cular os macroeconômicos e sociais. Procura também discutir as condiçōes que poderão propiciar e os possiveis efeitos da substituição de derivados de petróleo e a conservação, bem como os possiveis efeitos dessas medidas sobre a demanda de energia elétrica. (")

\section{Histórico}

A utilização da energia elétrica propagou-se, a partir do final do século passado, atingindo gradualmente a maioria das a tividades da sociedade moderna.

Esse desenvolvimento das aplicações da eletricidade compreende duas áreas, caracterizadas pelas potências elétricas (e intensidades de corrente) envolvidas:

- a das grandes potências, requeridas quando se exige força motriz calor ou efeitos especificos da ele tricidade, como a eletrólise:

$(*) 0$ autor agradece as sugestōes recebidas de Maria Teresa F. Serra,

incorporad as ao presen te texto.
- a das pequenas potências, como no caso das telecomunicações, da eletromedicina, da informática, etc.

Do ponto de vista energético, a primeira dessas categorias é que é significativa e a que será enfocada mais amplamente, a seguir.

A difusão do uso desse vetor energético deve-se, de um lado, à sua extrema versatilidade, tanto em termos da diversidade de suas fontes, quanto de uso $\mathrm{fi}$ nal. Assim, de um lado, a energia elétrica apresenta, para o país, importante vantagem econômica e estratégica e, de outro, traz para o usuário vantagens como a controlabilidade, divisibilidade. poluição e armazenamento nulos, confiabilidade de suprimento e seguranca na utilização relativamente elevadas, em re lação às demais modalidades de energia.

Desde o início do processo de expansão de seu emprego, que iniciou há cerca de cem anos, a energia elétrica, assim como o petróleo, vem competindo, com sucesso, com outras modalidades de energia, principalmente a nivel de uso final, em virtude de suas caracteristicas, apontadas acima. Combustiveis tradicionais, tais como o carvão e a lenha, foram deslocados (da locomotiva, por exem. plo), passando a ser utilizados na geração da própria energia elétrica, ou foram substituidos, mediante o emprego desse vetor, pela energia hidräulica, que até então só era aproveitada quando situada junto ao ponto de utilização, sob forma de energia mecânica.

Além de substituições tais como as acima exemplificadas, a eletricidade substitui mão-de-obra com o uso de ampla gama de aparelhos eletrodomésticos cuja potência individual não é significativa em termos energéticos, para o país, mas que, pela sua multiplicidade representa parte ponderável da demanda global dessa energia. $\mathrm{O}$ mesmo se dá com os aparelhos de iluminação.

Finalmente, além da substituição de combustiveis e de mão-de-obra, a energia elétrica deve sua expansão a inova. ções tecnológicas que, aproveitando caracteristicas especificas da eletricidade, viabilizaram a oferta de produtos e ser. viços totalmente novos.

Em 1983 o Brasil consumiu 141 TWh e produziu 162 TWh, os quais correspondem a $35 \%$ da energia colocada no mercado, equivalente a 134 milhōes de toneladas de petróleo conforme (9). No Quadro 1, a seguir, compara-se a evolução do Brasil com outras regiões, no to. cante à participação da energia elétrica no balanço energético global.

Observa-se que somente após a 2 a guerra mundial a energia elétrica adquiriu uma participação realmente significativa no balanço energético mundial. No Brasil, seja pela estrutura de produção, pela relativa vantagem oferecida pela

\section{QUADRO 1}

\section{ENERG IA PRIMÁRIA TOTAL E \% DESTINADA A PRODUÇĀO DE ENERGIA ELÉTRICA}

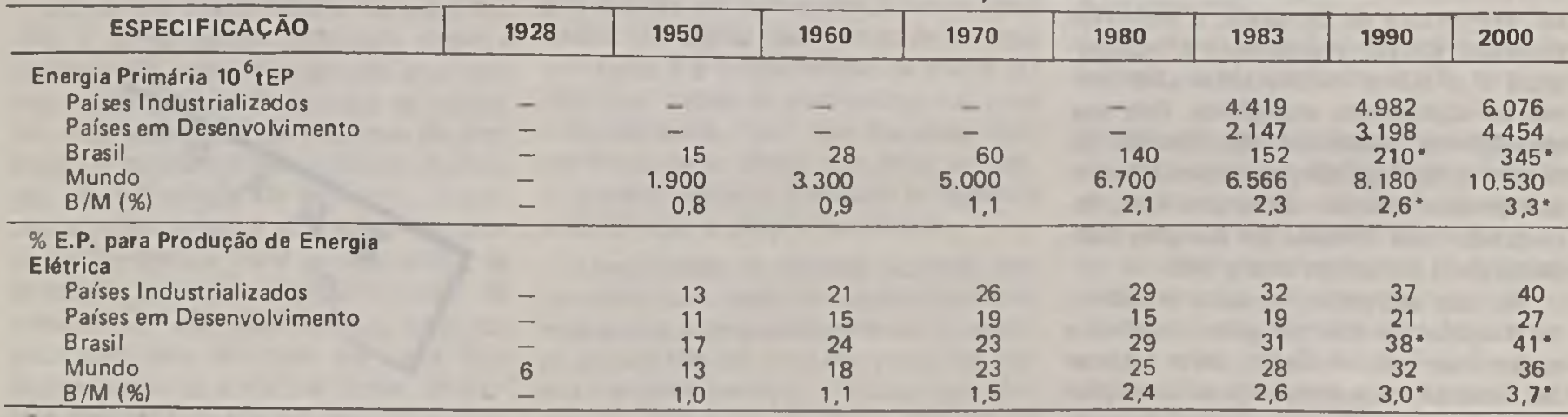

Valores estimados pelo autor

Demais valores obtidos a partir de: (9), (5), (8) e SIESE/MME. 
disponibilidade de fontes hidrelétricas ou por pequenas diferenças de critérios de conversão, a parcela de energia primária destinada a energia elétrica é semelhante à dos paises industrializados, devendo alcançar $41 \%$ em menos de vinte anos. O Quadro 1 também indica que, em 33 anos, de 1950 a 1983, a participação do Brasil no balanço energético mundial triplicou e que o consumo de energia elétrica apresentou crescimento mais acelerado.

Pode-se afirmar que a eletricidade foi fundamental para viabilizar a sociedade moderna tanto em termos da densidade de utilização de energia quanto pela de. pendência que essa sociedade apresenta em relação aos meios de comunicação que, por sua vez, requerem energia elétrica, embora em pequena monta, para seu funcionamento. Tão ou mais importante para essa sociedade, por dizer respeito a sua preservação, é o efeito positivo do uso crescente da energia elétrica sobre a eficiência energética global, seja pelas economias de escala que permite, seja pela elevada eficiência obtida em sua utiliza ção final, pelo mercado.

Observa-se (8) que, de 1960 a 1975 , - aumento da participação da energia elétrica no consumo global de energia dos países mais desenvolvidos foi signi. ficativa. Nesse mesmo período observase que as relaçōes dos crescimentos das demandas global e de energia elétrica para os crescimentos da economia dos respectivos países (PIB) apresenta uma correlação inversa, ou seja, aqueles em que a energia elétrica teve maior crescimento apresentam, proporcionalmente, menores crescimentos dos requisitos globais de energia, denotando a substituição de um componente menos eficiente por outro, mais eficiente, nos balanços energéticos.

Perspectivas de evolução do consumo de energia elétrica.

A evolução da demanda de energia elétrica é função da interação dos seguintes fatores, dentre os mais relevantes:

- a evolução sócio-econômica, com. preendendo o crescimento popula. cional, a urbanização e o desenvol. vimento econômico, destacando. se al a renda per capita e a distri. buição da renda:

- a estrutura de produção, os proces. sos tecnológicos, os hábitos de vi. da e condiçőes ambientais;

- as possibilidades de substituição de outras modalidades de energia, pela energia elétrica, onde intervém principalmente os custos unitários de utilização dessas energias e as eficiências com as quais são utilizadas;

- as perspectivas de conservação, em vista das tecnologias em uso e dos estímulos praticáveis, seja via preços, impostos, incentivos financeiros e outros meios destinados a induzir alterações tecnológicas.

Em paises em vias de desenvolvimen to, os fatores mais importantes do cres. seguintes, a substituição de modalidades de energia empregadas com baixa eficiência (a lenha, principalmente), por outras, de maior eficiência, tais como derivados de petróleo e eletricidade. além da expansão do emprego desta pela modificacão da estrutura do mercado, contribuíram significativamente para um maior crescimento da energia elétrica.

Na década de 80 a elevada elasticidade de energia global deve-se à relativa perda da importância do processo de

\section{QUADRO 2}

\begin{tabular}{l|cc|cc|c}
\hline \multicolumn{7}{c}{ BRASIL } \\
\hline \multirow{2}{*}{ Ano } & \multicolumn{2}{c}{ Pop. Total } & \multicolumn{2}{c}{ Pop. Urbana } & Urbanizacäo \\
\cline { 2 - 5 } & $10^{6}$ hab. $\%$ & $10^{6}$ hab. & $\%$ \\
\hline 1970 & 94 & - & 52 & - & 56 \\
1980 & 120 & 2,5 & 81 & 4,5 & 68 \\
1990 & 152 & 2,4 & 116 & 3,7 & 76 \\
2000 & 188 & 2,1 & 150 & 2,6 & 83 \\
2010 & 224 & 1,8 & 186 & 2,2 & 83 \\
\hline
\end{tabular}

cimento do consumo de energia elétrica são, provavelmente, o crescimento da população urbana, a evolução da produ. ção industrial, ambos acompanhados por um processo secular de substituição de combustiveis por energia elétrica, que se diferencia daquele mais recente, induzido por alterações bruscas nas relações entre preços da energia elétrica e dos combustiveis.

A perspectiva de evoluçáo da popula. ção brasileira, conforme(5), é a seguinte:

Estima-se que a economia brasileira, por sua vez, venha a crescer conforme indicado no Quadro 3 a seguir, segundo estudos adotados atualmente pelo Setor Elétrico para a previsão de sua demanda (5).

Avaliações do efeito da composição dessas variáveis, ou seja, resultados de estudos de previsãn da demanda, tam. bém apresentados no Quadro 3, indicam que o consumo global de energia elétri. ca poderả expandir-se de 5 a 6 vezes en. tre 1980 e 2010 . Nesse mesmo periodo os requisitos globais de energia primária poderão aumentar de 3 a 4 vezes.

No Quadro 3 observa-se que, exceto na década de 60 , o crescimento dos requisitos de energia global foi menor do que dos de energia elétrica. Naquela década, o recente advento da indústria automobilistica, e restrições remanscentes da oferta de energia elétrica foram fatores relevantes para acarretar um crescimento dos requisitos de eletricidade in. ferior ao da energia global. Nas décadas substituição acima referido, à expansão da produção de álcool e produção de bagaço e ao crescimento da eletricidade que, embora modesto em termos históricos, apresenta elasticidade de 2, $3 \mathrm{em}$ relação ao do PIB, sendo devido à expansão de indústrias grandes consumido. ras de energia elétrica e ao aumento da taxa de atendimento ou seja, da parcela da população atendida. A partir da déca. da de 80, a elevada e crescente participa. ção da energia elétrica no balanço energético e o fato da mesma ainda ser predominantemente de origem hidrica (embora em proporções decrescentes perto do final do periodo em estudol contribui para a baixa elasticidade indicada.

Também se prevê, no periodo em estudo, sensiveis esforços de conservação, seja de combustiveis, seja de eletricidade. Devido à expansão e à alteração da estrutura do mercado de energia elétrica previstas para os próximos anos, acredita-se que resultados decorrentes de um programa de conservação somente serāo aparentes, influindo significativamente no crescimento global da demanda, por volta do ano 2000 , conforme se depreende da redução da elasticidade na década de 90 . Após 2000 a elasticidade aumentaria então ligeiramente, indicando uma expansāo do pa pel da eletricidade, no balanço global já não mais atenuada pelo efeito do processo de implantação de medidas de conservação como na década de 90 . O crescimento tenderia a reassumir 
do país como supridor internacional de bens que requerem grandes quantidades de energia elétrica para sua produção. 0 quadro 6 indica as elasticidades da demanda de energia elétrica em relação ao PIB e os valores da relação EE/PIB, até 2000, para o Brasil e outras regiőes.

Tais parâmetros das previsర̄es dos requisitos brasileiros de energia elétrica, comparados aos de outras regiőes, no quadro 6 , permitem considerar que essas previsões são razoáveis, senão conservadoras, para o final do período estu. dado.

\section{Racionalização energética - substi- tuição e conservação}

A racionalização energética envolve tanto a substituição quanto a conse:va. ção, mediante as quais procura-se mınimizar o custo da energia a ser utilizada, como um todo, pelo pa ís.

A produção de bens e serviços requer, de um modo geral, a mobilização de mão-de-obra e matérias primas, dentre as quais a energia (elétrica ou de combustiveis): instalações e, portanto. capital e tecnologia; e ainda a gestão desses fatores de produção, que pode afetar, significativamente, os resultados ou seja, a eficiência do processo.

$A$ variação do custo de um ou mais fatores de produção, num processo, pode vir a requerer alteraç̋es na combina. ção desses fatores, no sentido de com. pensar aquela variação. Essa alteração pode se limitar à gestão, sem alteração das instalações e tecnologia, procurando-se operar o sistema existente com maior eficiência, menor desperdício de matéria prima, menor índice de refugo. etc. Pode também envolver alterações tecnológicas, com alterações mais ou menos amplas dos processos envolvidos. alterando coeficientes tecnológicos e/ou as matérias primas empregadas. Pode, finalmente, determinar mudanca de nível de produção, em busca de novo ponto de equil ibrio entre receita e despesa.

A formulação de políticas de racionalização energética poderá contemplar medidas genéricas tais como preços e divulgação de tecnologia, bem como atuar diretamente junto aos consumido. res mais expressivos, tendo em vista a concentração do uso da energia, seja a nível residencial, devida à concentração de renda, seja a nivel da indústria e ser. viços onde, em 1980, apenas 200 estabelecimentos eram responsáveis por $39 \%$ do consumo nacional de óleo combustí vel, sendo semelhante a distribuição da. quele de energia elétrica. Essa concentração propicia a obtenção de resultados expressivos, em prazos relativamente curtos.

\section{Substituição de combustlveis por energia elétrica}

A substituiçăo de combustiveis por energia elétrica ou outra modalidade de energia pode ser julgada, a nivel macro, com base nas prioridades da política econômica do pa is, tais como o equilí. brio do balanço de pagamentos, a redução da inflação e da dependência externa, particularmente na área energética, $\mathrm{e}$ no desenvolvimento tecnológico, procurando-se aumentar a participaçäo de recursos nacionais e renováveis na oferta de energia do país.

Pode ser avaliada do ponto de vista do consumidor, que, no cur to prazo, pelo menos, julga o tipo de fonte energética que lhe convém usar com base nos preços desta e nos demais insumos de 'seus processos de produção e em fatores tais como a garantia de suprimento, a facilidade de substituição de um insumo energético por outro, sua facilidade de estocagem, a qualidade do produto final, etc. A médio e longo prazo, sua escolha poderá estar integrada numa po. lltica de maximização de lucros que contemple uma mudança do processo de produção mediante o emprego de outra tecnologia. Esta mudança será considerada sobretudo pelas condiçōes de financiamento, além das diferenças de custos operacionais.

Apresenta-se, a seguir, algumas consideraçōes de ordem econômica e técnica sobre a substituição em questão, enfocando seu principal campo de aplicação, que é a substituição do óleo com. bustivel. A maior parte das substituiç̃es que envolvem os demais derivados. por serem empregados principalmente em meios de transporte (gasolina e óleo diesel) e para aquecimento e cocção (GLP), ou requerem investimentos iniciais muito pesados ou não são economicamente, ou mesmo tecnicamente, viáveis.

Vantagens e limitações da substituição do óleo combustível pela energia elf trica

Dentre as vantagens que o emprego da energia elétrica oferece, em relação ao dos combustíveis, destacam-se a flexibilidade e facilidade de controle das operações, o fato de não contribuir para a poluição ambiental, propiciar melhor qualidade dos produtos e menor indice de perdas de material e energia Neste sentido a eletricidade apresenta eficiências elevadas na medida em que seu dispêndio pode, em muitos casos, concentrar-se no espaco ou material efetivamente requerido, reduzindo assim, significativamente, seu desperdício. Permite também eliminar áreas $e$ instalações de estocagem de ccmbus tiveis e, finalmente, na maioria das re regiões atendidas pelos sistemas interligados, oferece elevada garantia de su primento

Parte significativa (cerca de $80 \%$ ) do óleo combustível ora utilizado na indús. tria é tecnicamente substituivel por energia elétrica: cerca de $70 \%$ é utilizado em caldeiras e fornos de aquecimen. to indireto, enquanto $30 \%$ é utilizado em processos diversos (fornos de aquecimento direto, forca motriz). Entretanto, em virtude das características técnicas dos processos e/ou das tecnologias dis. poniveis, a eletricidade não pode subs. tituir os combustiveis em processos como a fabricação do cimento e outros (que somam cerca de $20 \%$ ), em que esses fornecem, além do calor, a atmosfera redutora necessária ao processamento dos materiais envolvidos.

Em geral, a energia elétrica é utiliza. da com eficiência elevada, enquanto os combustiveis apresentam eficiências muito variadas mas sempre mais baixas do que a da energia elétrica. Por outro lado, a eletricidade, particularmente a de origem hidráulica, é um produto eminentemente capital-intensivo. Por isso, somente a partir de determinadas relaçōes entre custos unitários da eletricidade e dos combustíveis, associadas a diferenças de rendimento dos processos, é que se tornam nítidas as vantagens da substituição desses combustíveis pela energia elétrica.

Convém ressaltar que esses dois parâmetros, preços e rendimentos, não são suficientes para avaliar a direção do mercado de energia no tocante a essas subs tituições, pois outras vantagens da energia elétrica, mencionadas acima e de dificil mensuração e tradução em termos de preços, especialmente a longo prazo, poderão suplantar eventuais diferenças de custo, pelo menos do ponto de vista dos consumidores.

Além disso, é importante distinguir entre a substituição em instalações existentes, que apresenta geralmente menor flexibilidade e custos de adaptação elevados, daquela em que se considere, quando da implantação das instalações. utilizar energia elétrica onde tradicional. 
mente se utilizava óleo, permitindo explorar mais facilmente as vantagens da energia elétrica, adequando processos e o próprio "lay-out" daquelas instalaçōes.

Por fim, cabe lembrar também que, em alguns casos, outras fontes como o gás natural, o carvão, a lenha e outros derivados da biomassa constituem soluçōes mais econômicas do que a energia elétrica na substituição do óleo combustivel.

Fatores técnico econômicos mais relevantes na substituição

Dado que 1 tonelada de óleo com. bustivel tem poder calorífico(9) de $10.400 \mathrm{Mcal}$ e $1 \mathrm{MWh}$ equivale a 860 Mcal, se ambos fossem utilizados com a mesma eficiência, seriam necessários 12,1 MWh para substituir 1 tonelada de óleo. Entretanto, como a energia elétrica é utilizada com eficiências maiores do que o óleo, as relaçōes de substituicẫo situam-se mais freqüentemente entre $10 \mathrm{MWh} / \mathrm{t}$ e $3 \mathrm{MWh} / \mathrm{t}$, podendo inclusive alcançar valores inferiores a este último, embora raramente envolvendo quantidades significativas de onergia. Considerando um custo para o país de US\$ $30 / M W h$ para a energia elétrica entregue ao consumidor industrial, esta seria competitiva com o óleo que custasse de US $\$ 300 / t$ a US $\$ 90 / t$, respectivamente. Portanto, com base exclusivamente nesses custos, o ponto de equilibrio, para os valores atualmente atribuidos ao óleo combustivel, situa-se no entorno de 6 a $7 \mathrm{MWh} / \mathrm{t}$.

Entretanto, há outros fatores que usualmente influenciam a decisão de realizar essa substituição, dentre os quais a redução da poluição ambiental, causada pela queima do óleo. Esse benefício é função da localização do consumidor, sendo particularmente importante em áreas densamente povoadas ou onde já ocorre elevado grau de poluição. A avaliação desse beneficio é complexa, mas pode-se apresentar uma estimativa, baseada no custo de redisi-la, da ordem de US $\$ 40 /$ de óleo substituído (3).

A substituição, como a de fornos a öleo por fornos elétricos pode acarretar melhoria na qualidade dos produtos, principalmente quando esta é sensivel aos efluentes da combustão. 0 valor des. te benefício, bem como o de reduçōes na perda de matéria prima varia caso a caso. Tais vantagens, entretanto, ocorrem quando há uma mudança essencial de processo, o que não acontece quan- do a substituiçāo se restringe, por exemplo, ao sistema de produção de vapor, a $m$ inos que os efluentes da queima do óleu afetem os produtos.

A redução de consumo de derivados de petróleo não apenas beneficia o país, como reduz as despesas de transporte. Assim, em princípio, quanto mais afastado dos pontos de suprimento, mais vantagens apresenta um consumidor de energia que realize a substituição, principalmente quando a modalidade de transporte requerida seja grande consumidora de óleo combustível.

Há, por outro lado, que se considerar dois custos importantes associados à substituição: o da adaptação do consumidor e o das instalaçōes do setor elétrico necessárias para atendê-lo.

$O$ investimento do consumidor varia significativamente de até menos de US\$ $50 / \mathrm{kW}$ até mais de US $\$ 500 / \mathrm{kW}$ de car ga requerida. No extremo inferior estão geralmente as instalações de caldeiras, quando a capacidade da subestação do consumidor é suficiente para atendè-la. As substituiçōes que apresentam maiores eficiências (e geralmente menores potências) tendem a se situar no extre. mo superior daquela faixa, como os fornos de indução. Esses custos mais eleva. dos são geralmente compensados pelo ganho de eficiência: uma substituição que requeira $3 \mathrm{MWh} / \mathrm{t}$, quando o custo do óleo competitivo com a eletricidade a US\$ 30/MWh é de US\$90/t, sem computar outros custos, ainda seria competitiva com o óleo a cerca de US\$ $130 / t$, caso o custo de adaptaçăo fosse de US\$ 500/kW, incorporando-se ao custo operacional os custos usuais de capital, supondo-se ainda a utilização do equipamento durante 5000 horas por ano.

Os investimentos e demais custos para o setor elétrico variam segundo a lo. calização geográfica, o porto da carga e seu regime horosazonal de operação. $\mathrm{Pa}$ ra um dado nivel de tensão, os custos médios de suprimento variam numa relação de 100 para 78, aproximadamente, para uma carga que opere durante cerca de $\mathbf{5 0 0 0}$ horas por ano, isto é, com fator de carga de $57 \%$, que é usual, dependendo apenas da forma de sua variação horária. Uma carga que apresente sensivel redução nas horas em que a demanda do sistema é maior não estará afetando a adequação dos sistemas de suprimento, não contribuindo, portanto, para tornar necessária sua expansăo. Entretanto, uma carga que apresente solicitação no horário de ponta contribui para a neces- sidade de investir na capacidade de ponta das usinas e naquela dos sistemas de transmissão e distribuição, além de receber energia no momento em que o ni. vel de perdas é mais elevado, contribuindo assim para aumentar o custo de seu suprimento.

Num sistema elétrico cuja base energética é predominantemente hidráulica, ocorrem periodos cuja freqüência e duração é aleatória, em que a disponibilidade de energia é superior àquela garantida e que, portanto, pode ser fornecida a custo da ordem de US\$10/MWh, mui to inferior ao daquela. Assim, substituiçōes temporárias, cuja demanda de ener. gia seja interruptível, poderão aproveitar esta modalidade de suprimento, compensando a pequena vantagem na variação de eficiência por uma vantagem em termos do custo da eletricidade, como nos sistemas bi-energéticos. A geração de vapor, um dos maiores consumidores de calor, é uma das aplicações adequadas a essa energia.

Caracterizam-se assim as substituições como temporárias lou interruptiveis) e permanentes, variando ambas também conforme maior ou menor demanda da nova carga no horário de maior demanda do sistema.

De um modo geral, são os seguintes os processos industriais mediante os quais pode-se substiruir combustíveis por energia elétrica, nos quais esta atua, principalmente, pela produção de calor (efeito Joule), radiação, força motriz e ionizaçāo:

- Aquecimento indireto por resistências (fornos e secadores)

- Aquecimento direto por resistências (resistências de imersão)

- Aquecimento por passagem direta da corrente elétrica (substâncias condutoras)

- Aquecimento por induçã̉o lefeito Joule devido a correntes eletromagneticamente induzidas)

- Secagem por bomba de calor (reaproveitamento da energia contida no vapor d'água de corrente do processo)

- Recompressão mecânica do vapor (destilação e concentração)

- Separação de liquidos por mem. branas (substituição de energia térmica por mecanica)

- Radiações infravermelhas (altas densidades e pequena inércia) e ultravioletas (efeitos fotoquímicos substituem o calor) 
- Altas e hiperfreqüências (aqueci mento induzido na massa de maus condutores de calor)

- Plasmas térmicos (temperaturas extremamente elevadas - cerca de $10.000^{\circ} \mathrm{C}$ - para processos de fu sāo, solda, etc.)

Dentre os equipamentos baseados nessas aplicações da eletricidade, os mais importantes, do ponto de vista de sua contribuição para a demanda global de energia são as caldeiras elétricas, cujas potências são de centenas de $\mathrm{kW}$ a deze nas de MW, e os fornos de resistência e indução, com potências menores, de de zenas de $\mathrm{kW}$ a cerca de uma dezena de MW. Futuramente, os plasmas térmicos poderão ter um papel tão ou mais rele vante que as caldeiras, pois exigem po tências da ordem de até várias dezenas de MW e apresentam ganhos de rendimentos superiores àqueles obtidos na substituição de caldeiras a óleo por elẻ tricas, além de outras vantagens ineren tes aos processos nos quais são empre gados. Para as caldeiras e fornos elétricos, são os seguintes os dados característicos.

Caldeiras: em função da capacidade (toneladas de vapor por hora) desejada, utilizam-se caldeiras a resistência ou de eletrodo submerso, supridas em baixa tensão, para produçōes até cerca de 3 $t / h$, ou caldeiras supridas em alta tensão, de eletrodo submerso ou jateado, para produções elevadas (até $20 \mathrm{t} / \mathrm{h}$ ou superiores). Grosso modo, são requeridos 0,7 MW de potência elétrica por $t / h$ de capa. cidade de produção da caldeira.

O investimento varia de US\$ 40 a US\$ $15 / \mathrm{MW}$, para a caldeira, mais US\$ 5 a US\$ 40/kW, nas instalações do consumidor, inclusive sua subestação abaixadora.

Fornos: para fusão de metais pode-se utilizar fornos de indução (de cadinho ou a canal), sendo que as potências se situam usualmente na faixa de $50 \mathrm{~kW}$ a $1.000 \mathrm{~kW}$ em maiores, apresentando consumos da ordem de $300 \mathrm{kWh} / \mathrm{t}$ a 500 $\mathrm{kWh} / \mathrm{t}$, em função do metal do forno, a custos de investimento de US $\$ 600 / \mathrm{kW}$ a US\$150/kW, inversamente proporcio. nais à potência requerida, e acrescentando custos de instalação, que variam de US $\$ 45$ a US\$140/kW. Pode-se tam. bém empregar fornos de resistência, cujo custo unitário varia de US\$ 100 a US\$ $300 / \mathrm{kW}$, sendo os custos de instalação semelhantes àqueles para os fornos de indução, porém limitados, normalmente, a potências mais baixas. Os fornos de resistência também são usados para materiais não metálicos, como produtos cerâmicos.

A nivel doméstico e de serviços, o uso mais amplo da energia elétrica, além do condicionamento ambiental, depende da economicidade de seu uso para aquecimento d'água e cocção, o que, entre outros fatores, depende dos custos de suprimento e da possibilidade de exercer tais utilizações em horários específicos, fora daquele da ponta da carga.

Finalmente cabe indicar, conforme (2), que, para o nível de consumo e estrutura de usos de 1980 , em que o valor global dos requisitos de energia foi de 140 milhões de tEP, o óleo combus tível constituindo $12 \%$ desse total, a parcela economicamente viável de subs tituição era de 2,1 milhões de tEP, re querendo 14,3 milhões de MWh. Ainda com referência ao ano de 1980, o potencial de substituição indicado representa $12 \%$ do consumo global verificado naquele ano. As substituiçőes permanentes apresentam um potencial significativo. para a economia do país e para a racionalização de seu balanço energético. Parte dessa substituição foi alcançada com base em tarifas especiais e financia. mentos para adptação de equipamentos. Por outro lado, inovações tecnológicas. mais do que reduções importantes nos custos da energia elétrica (que são im. prováveis) poderão acarretar, a longo prazo, importantes acréscimos do potencial de substituição, destacando-se o plasma, seja pelas potências requeridas seja pela amplitude de seu campo de aplicação.

\section{Conservaçåo}

A conservação de energia ou redução da quantidade de energia originalmente empregada, sem prejuizo da quantidade e qualidade do produto ao qual se destina, envolve, além de medidas econô. micas, tecnológicas e gerenciais, uma mudança de atitude frente a bens escassos como a energia e equivale a uma fon. te de energia renovável, imediatamente acessivel, freqüentemente a custos inferiores àqueles requeridos para expandir a oferta de uma fonte equivalente. A prática da conservação é, assim, essen. cial para a preservação das fontes primárias de energia e de outros recursos, acarretando economias globais singificativas.

Dentre as aplicaçōes da energia elétrica, encontram-se inúmeras e varia. das oportunidades para conservação. destacando-se a iluminação pública e de interiores, os refrigeradores, o acionamento eletromecânico, a reciclagem de recursos energéticos secundários da indústria, o projeto e os materiais empregados na construção civil, processos de aquecimento e eletroquímicos, melhorias nos processos de gestão dos sistemas produtivos, etc.

Conforme o campo de aplicação, a conservação pode proporcionar, economicamente, reduções do consumo superiores à metade de seu valor original, como na substituição de lâmpadas incandescentes por lâmpadas fluorescen. tes de alta eficiēncia. Refrigeradores apresentam possibilidades de redução de seu consumo para cerca da metade. Em diversos processos industriais, o controle de acionamento eletromecânico e melhorias nas condiçōes de isolamento térmico permitem significativas economias.

Entretanto, não apenas a disponibilidade dos meios - equipamentos, tecnologia, recursos financeiros - é neces. sária. É preciso que os preços da energia sejam representativos de seu custo para a sociedade, para que esta seja adequa. damente orientada por tais preços, em seu comportamento. E é necessária uma atitude, que pode ser institucionalmente promovida e tornar-se um componente cultural, no sentido de priorizar a conservação. Esse elemento é importante mormente face à tendência dos consumidores privados de escolherem seus equipamentos em função do custo inicial dos mesmos. Até mesmo em sociedades mais ricas e que vêm sendo orien. tadas em relação à conservação, a "taxa de desconto.jmplicita" (6) do sobrepreço de equipamentos, atribuivel ao ganho de eficiência, apresenta valores significa. tivamente mais elevados do que a taxa de juros do mercado, exceto para com. pradores de rendas mais elevadas, provavelmente menos afetados pela economia proporcionada pela conservação do que pelo seu conteúdo sócio-cultural.

A divulgação de meios necessários e a criação de uma mentalidade sensível à conservação, como a aplicação de selos de eficiência a equipamentos tais como refrigeradores, são, portanto, essenciais a esse componente da racionalização do uso da energia.

Finalmente, a quantificação de seu potencial e, principalmente, a previsão de que parcela desse potencial será realizada é extremamente difícil, por de. pender de grande número de variáveis e de decisões, de diversas naturezas. Em. 
bora alguns resultados possam ser obtidos a curto prazo, sem investimentos significativos, medidas de conseqüências mais amplas apresentam inércia considerável. A exemplo de outros países, seria razoável admitir, num prazo da ordem de 15 anos, reduções dos requisitos globais de energia elétrica, em relação àqueles que ocorreriam se as medi. das de conservação não fossem adotadas, da ordem de $10 \%$ a $20 \%$, bem inferiores, todavia, ao provável valor potencial de conservação.

\section{Considerações finais}

Cabe por fim, comentar, ainda que sucintamente, a importância dos preços para a expansấo da demanda de energia elétrica. Dada a complexidade das tarifas (e seus complementos), a variação de cada um de seus componentes, bem como a da estrutura tarifária, afeta diferentemente os diferentes segmentos do mercado de energia elétrica.

Restringindo esta discussão às variacōes do nivel tarifàrio médio, a resposta da demanda, ou elasticidade-preço do mercado, pode ser avaliado a curto e a longo prazo: a curto prazo os consumidores podem colocar em prática alguma medida simples de conservação, repassar os custos a seu mercado ou alterar o $\mathrm{ni}$ vel de produção, caso a demanda de seu produto seja modificada; a longo prazo, entretanto, podem surgir modificações nas instalações e estrutura do consumidor, com alteraçōes mais profundas do mercado.

As avaliações da elasticidade-preço, disponiveis no Brasil, para as várias catogorias de consumo de eletricidade. apresentam valores bastantes diferentes e referem-se a situações nem sempre aconselháveis àquelas esperadas no futuro. De um modo geral, embora haja consenso quanto à importáncia dos preços, há controvérsia e incerteza quanto ao valor do efeito de sua variação(1). Tal incerteza fundamenta-se na possivel dependência da elasticidade-preço de diversos fatores, tais como a estrutura do mercado, o nivel inicial dos preços, a taxa de inflação, os preços das energias concorrentes, etc.

Conseqüentemente, à avaliação do efeito da variação dos preços por métodos estatísticos, calcada sobre uma situação verificada, mas passada e comple. xa, pode-se contrapor uma avaliação analítica, que procure avaliar indepen. dente e concomitantemente efeitos de variações de preços tais como conserva. ção, substituição e variação de nível de demanda dos produtos.

Acredita-se que, no Brasil, onde o mercado de produtos industrializados é bastante fechado e, no setor residencial, é elevada a concentração de renda e mais, onde o nivel de inflação é elevado e, como no resto do mundo, a eletricida de constitui um componente minoritário da maioria dos produtos finais, variações usuais do valor real dos preços nãn afetará significativamente a demanda, a menos que seja alcançado, para algum processo, o limiar de competição com outra modalidade de energia ou de em. prego de outra tecnologia, ainda elétri. ca, ou, para produtos de exportação, que não podem repassar a seus mercados significativas variações de custo final, seja alcançado o nivel de custo que os coloca fora do mercado.

Assim, a elasticidade-preço seria re. presentada por uma curva de compor. tamento altamente irregular, que apresentaria patamares de valores muito baixos, intercalados de saltos, a cada novo limiar de substituição ou competição internacional alcançado, sendo o valor desses saltos função da importância do mercado envolvido por aquele limiar.

Para finalizar, cabe observar que aos niveis atuais de preços das diversas modalidades de energia e mesmo admitindo uma elevação daquelas da energia elétri. ca, não se acredita que a evolução do mercado global venha ser profundamente alterada pelos processos de conservação e substituição, dado que os efeitos, dos mesmos, em certa medida, tendem a se compensar.

Por outro lado, como não se prevê redução de custos de suprimento de energia elétrica e, portanto, dos preços aos quais é ofertada, o fator realmente importante para a expansão da demanda de energia elétrica é a evolução da natureza e do porte do mercado, traduzidos pela elasticidade-renda e pelo crescimento do PIB. Para ilustrar essa colocação, observa-se que, para um crescimento do PIB a $6 \%$ a.a. e elasticidades de 1,67 ou 1,33 , que conduzem a crescimentos da demanda de $10 \%$ ou $8 \%$ a.a., os requisitos globais ao final de vinte anos variam de $44 \%$. Dado o custo e outras limitações para expandir a ofer. ta de energia elétrica, muitas economias procuram "desvincular" seu crescimento econômico da demanda de energia, o que é parcialmente factivel, a nivel de algumas regiōes, na medida em que pos. sam retendenciar seu perfil produtivo.
Tal alteração freqüentemente envolve a transferência de indústrias de elevado consumo de energia elétrica para outras regiões, o que sugere importante limita ção desse processo, com relação a países em vias de desenvolvimento, em virtu de das alternativas de trocas internacio nais com que estes paises contam.

\section{BIBLIOGRAFIA}

1. Brandão, P. V., A. G. Busse e A.C de Queiroz, Elasticidade-Renda, ElasticidadePreço Pura e Cruzada, e Elasticidades de Outros $F$ atores que influem na Demandade Eletricidade. ELETROBRÁS/ DEME, Nota Técnica 25, 1984.

2. Busse, A.G. M T.F. Serra e P. Erber, Subs tituição de Óleo Combustível por Energia Elétrica e ELETROBRÁS/DEME. Nota Técnica 20, 1982

3. Erber, P. Substituição de Derivados de Pe tróleo por Energia Elétrica, Metodolo. gia para Análise Económica, abril de 1985.

4. Frisch, J.R. Énergie 2000-2020: Equilibre Mondial et Tensions Régionales. $12^{\mathrm{e}}$ Congrès de la Conférence Mondiale de l'Énergie, New Delhi, Sept. 1983.

5. GCPS/CTEM - Mercado de Energia Elètrica 1984/2005, Brasil e Regiōes Eletricas, Relatório Executivo, janeiro de 1985.

6 Goldemberg, J. e R. H. Williams, The Economics of Energy Conservation in Developing Countries: The Consumer ver. sus the Societal Perspective. Draft, April 1985.

7. Hafele, W. Energy in a Finite World, A Global Systems Analysis. Cabridge, Man: Ballinger, 1981.

8. International Atomic Energy Agency, Energy and Nuclear Power Planning in Developing Countries. Tecnical Report Series no. 245, Vienna, 1985.

9. Ministério das Minas e Energia, Balanço Energét ico Nacional, 1984. 